\title{
Linking HIV-positive family planning clients to treatment and care services in Kenya
}

Wilson Liambila

Population Council

Francis Obare

Population Council

Harriet Birungi

Population Council

Ruth Wayua Muia

Joyce Wanderi Maina

See next page for additional authors

Follow this and additional works at: https://knowledgecommons.popcouncil.org/departments_sbsr-rh

Part of the Demography, Population, and Ecology Commons, Family, Life Course, and Society

Commons, Health Policy Commons, Immune System Diseases Commons, International Public Health

Commons, Medicine and Health Commons, Virus Diseases Commons, and the Women's Health

Commons

How does access to this work benefit you? Let us know!

\section{Recommended Citation}

Liambila, Wilson, Francis Obare, Harriet Birungi, Ruth Wayua Muia, Joyce Wanderi Maina, Mary N. Maina, Christine Awuor, and Ibrahim Mohammed. 2011. "Linking HIV-positive family planning clients to treatment and care services in Kenya," APHIA II Operations Research Project in Kenya Report. Nairobi: Population Council. 


\section{Authors}

Wilson Liambila, Francis Obare, Harriet Birungi, Ruth Wayua Muia, Joyce Wanderi Maina, Mary N. Maina, Christine Awuor, and Ibrahim Mohammed 


\section{APHIA II Operations Research Project in Kenya}

\section{3-A-00-09-00001-00}

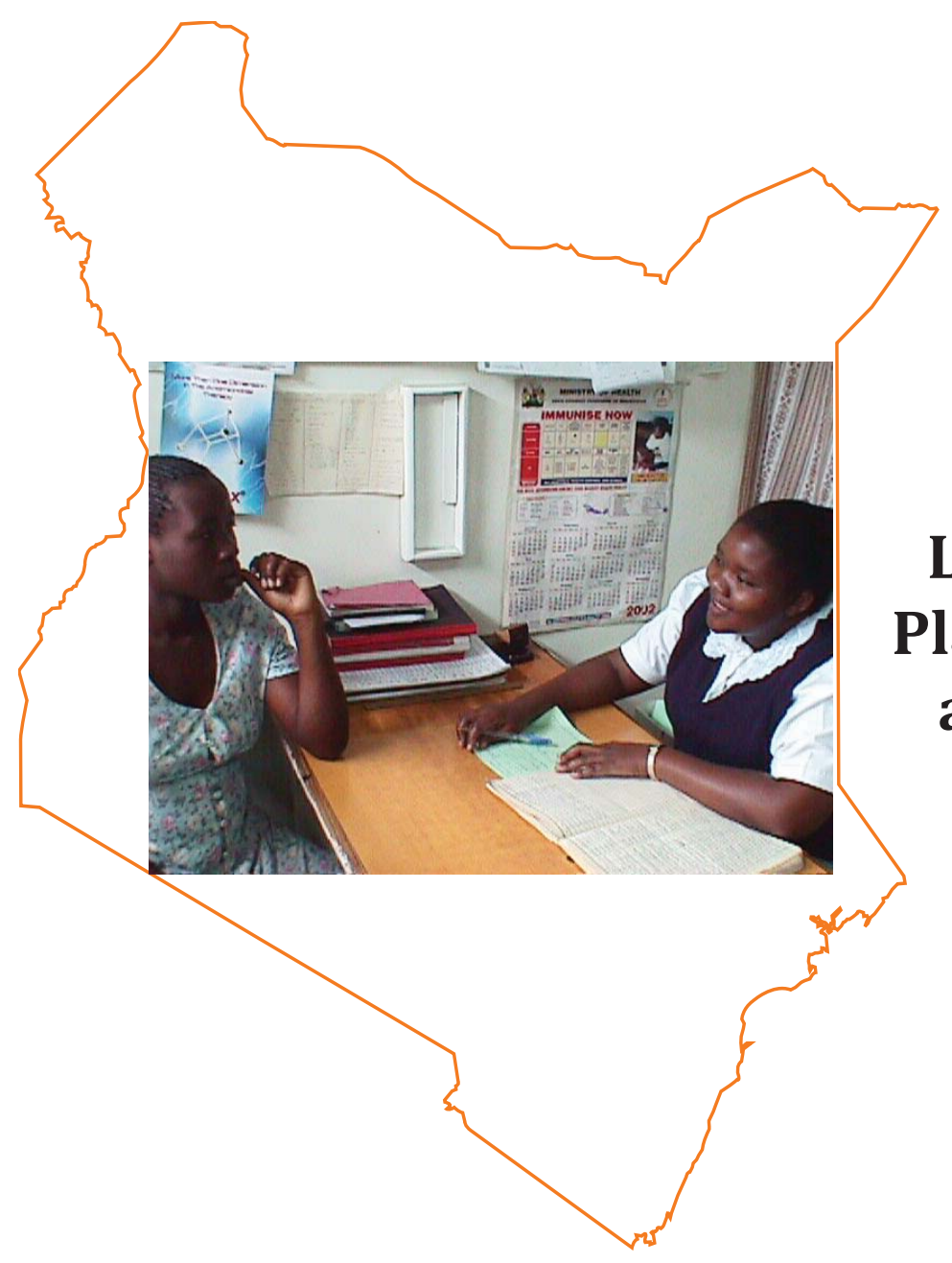

Linking HIV-Positive Family Planning Clients to Treatment and Care Services in Kenya

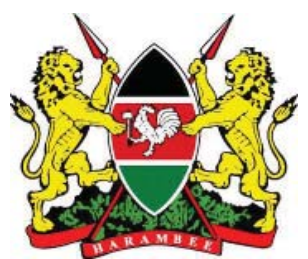




\title{
Linking HIV-Positive Family Planning Clients to treatment and care services in Kenya
}

\author{
APHIA II Operations Research Project/ Population Council \\ Wilson Liambila, Francis Obare, Harriet Birungi
}

Ministry of Public Health and Sanitation, Kenya

Ruth Wayua Muia, Joyce W. Maina, Mary N. Maina

Ministry of Medical Services, Kenya

Christine Awuor, Ibrahim Mohammed

February, 2011 


\section{Table of Contents}

Acknowledgments ...............................................................................................ii

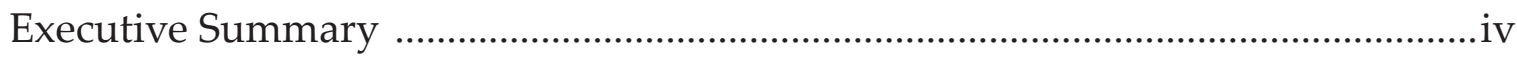

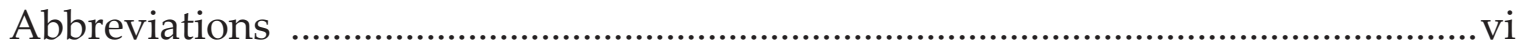

Background and Problem Statement ……………………................................... 1

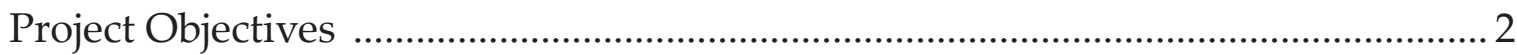

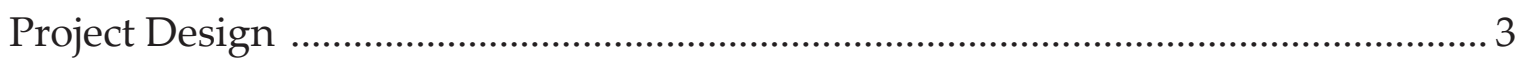

Intervention development, implementation and monitoring ………………….... 4

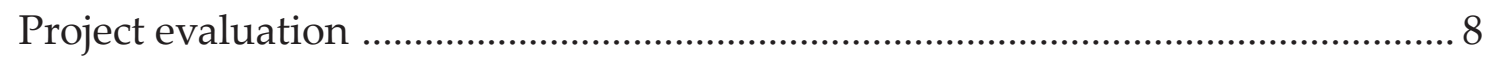

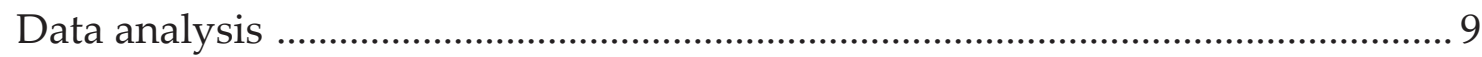

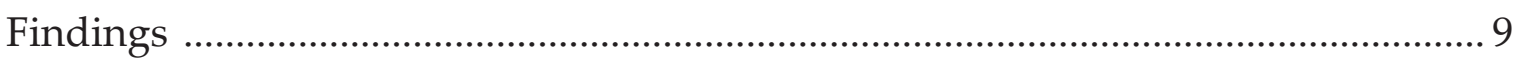

Characteristics of clients whose records were reviewed ……………………….... 9

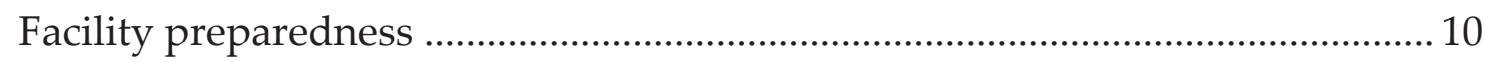

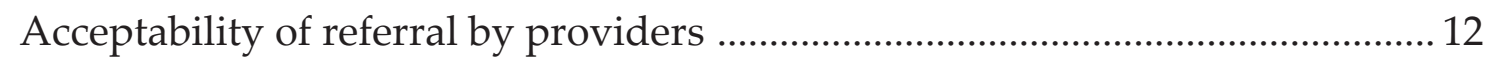

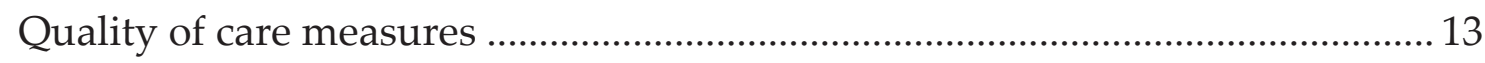

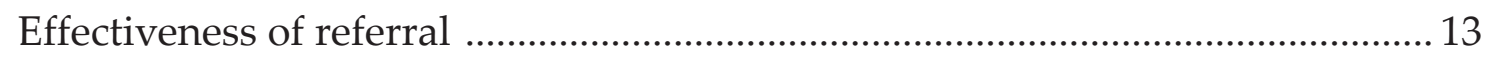

Discussions, Conclusions and Recommendations .................................................... 14

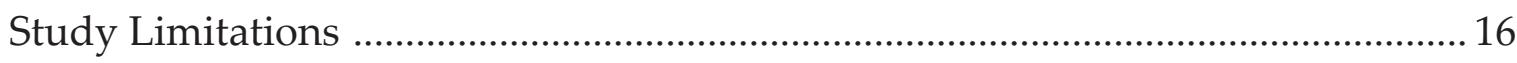

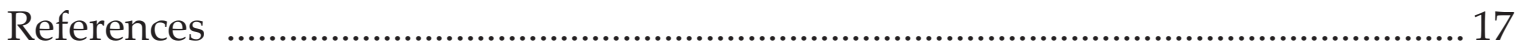

Annex 1: Directory of health facilities providing care and treatment including STIs, further investigations and other services to the referred clients or

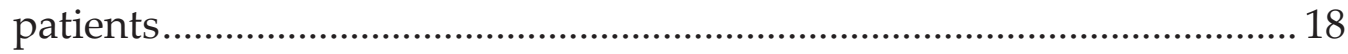

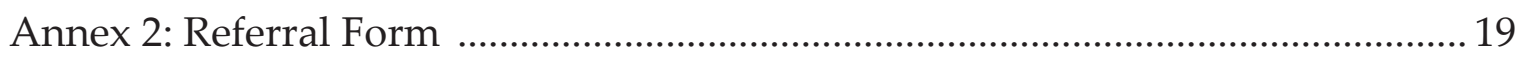

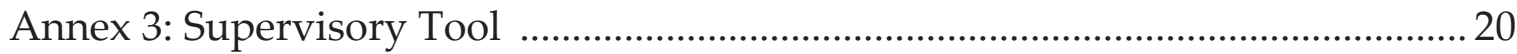




\section{Acknowledgments}

Successful planning, implementation and evaluation of the activities reported in this document were accomplished following important inputs from various institutions and individuals.

The National HIV/AIDS and STDs Control Programme (NASCOP) and the Division of Reproductive Health, Ministry of Public Health \& Sanitation, Kenya, are acknowledged for their leadership in coordinating the implementation of the study on Linking HIV-positive family planning clients to treatment and care services in Kenya. In particular, we wish to thank Dr. Bashir Issak and Dr. Bartilol Kigen (formerly Acting Head, Division of Reproductive Health, Ministry of Public Health \& Sanitation and Dr. Ibrahim Mohammed (Head, Care and Treatment-NASCOP) for coordinating the implementation of the study activities.

We would like to thank Dr. Ian Askew, Director, Reproductive Health Services and Research, Population Council for reviewing the study proposal and the report.

Members of the Provincial Health Management Team (Central Province), District Health Management Team in Nyeri: the District Medical Officer of Health, District Public Health Nurse, District Medical Laboratory Technologist, Caroline Wanjohi (DASCO), and all mentors and mentees are acknowledged for having taken part and supported project activities in all phases.

Members of the Provincial Health Management Team (Central Province) especially Dr. Mwangi Rumunyu (PASCO) and Agnes Gichogo (PRH coordinator), District Health Management Team in Thika: the District Medical Officer of Health, District Public Health Nurse, District Medical Laboratory Technologist, Damaris Kasyoka (DASCO/Trainer), and all mentors and mentees are acknowledged for having taken part and supported project activities in all phases.

Hospital Management teams, in particular the Medical Superintendents and the Nursing Officer incharges as well as the officers in-charge of the MCH-FP units are acknowledged for monitoring and supervising project activities. Kezziah Ruraya- MCH/FP Nursing officer in-charge deserve special appreciation for her contribution in coordinating activities in Gatundu District Hospital.

We wish to thank Erick Oweya for data analysis and the data collection team: Dr Ann Macharia, Damaris K. Mwanzia, Sarah Wangui Mwema, Alice Kamau, Beatrice Mwai, Millicent Kiarie, Allan Mwai, Grace W. Mwangi, Lilian Mwatha, Catherine W. Kuria and Ann Gichuhi.

This publication has been made possible with the generous support of the American people through USAID/Kenya, under the APHIA II Operations Research Project, a cooperative agreement No. 623-A-00-0900001-00 between the Kenya Mission and the Population Council. The opinions expressed herein are those of the authors and do not necessarily reflect the views of USAID.

Suggested Citation: Liambila W., Obare F., Birungi H., Wayua Muia R., Maina J., Maina M., Awuor C., Mohamed I., (2011) Linking HIV - Positive Family Planning Clients to Treatment and Care Services in Kenya; APHIA II OR Project in Kenya/ Population Council: Nairobi, Kenya

(C) 2011, The Population Council, One Dag Hammarskjold Plaza New York, New York, 10017, www.popcouncil.org. The document may be freely reviewed, abstracted, reproduced or translated, in part or in whole, but not for sale nor use in conjunction with commercial purposes. 


\section{Executive Summary}

In recent years, there has been interest in the integration of HIV/AIDS and other Reproductive Health services, as a means of improving clients' access to both types of services, improve efficiency and reduce costs. In Kenya, different approaches have been tested, including integrating HIV into Family Planning services and integrating Family Planning into HIV services. The government has also developed a national Reproductive Health and HIV/AIDS integration strategy which emphasizes the need to provide coordinated RH and HIV integrated services across the two programs.

Under the USAID-funded FRONTIERS Program, the Population Council tested two models of integrating HIV counselling and testing (CT) into Family Planning (FP) services. The two models involved 'testing' and 'referral' of FP clients - in the "testing" model, FP providers were trained to offer CT services and post-test counselling to FP clients during the same visit while in the "referral" model, FP clients were counselled on HIV prevention and testing, and then referred to a specialized CT facility for services. When the project was evaluated, it was found that integrating STI/HIV counselling and testing within FP services was feasible and acceptable to clients and providers. It also led to significant improvement in the quality of care provided, and between 50-75\% of the women seeking FP services who were offered an HIV test accepted it.

However, a major limitation was that FP clients who tested HIV-positive were not actively linked to care and treatment services, including antiretroviral treatment (ART), and screening and management of sexually transmitted infections (STIs). The health providers simply advised the clients to attend any of the health facilities (mainly hospitals) that had comprehensive care centres (CCCs) for managing HIV/ AIDS. This made it difficult to establish whether the clients received the necessary services. To address this gap, APHIAII Operations Research (OR) Project and the Ministry of Health developed and tested a modified approach for linking HIVpositive FP clients to HIV care and treatment and STI services. The research goal of the project was to design and test a referral framework for linking HIV-positive FP clients to treatment and care in selected health facilities; assess the acceptability of the proposed referral framework to providers; and assess its effectiveness in increasing the number of eligible HIV-positive FP clients received at HIV care and treatment services. The intervention involved five activities implemented over a period of six months in six facilities:

- Strengthening the referral system for HIV-positive FP clients

- Review of existing training materials and job aids

- Updating service providers with referral system information

- Strengthening health facility supervision activities

- Strengthening health management information systems 
The findings of the project evaluation show that the referral mechanism put in place was effective $-93 \%$ of the HIV-positive FP clients received at CCCs had been referred from the MCH/FP unit of the same facility. Some facilities also received HIV-positive clients seeking FP services referred from other facilities. There was a significant increase in the proportion of FP service providers reporting having a directory of HIV/AIDS/CCC facilities in their locality and to which they could refer FP clients testing HIV positive. There was also a significant increase in the proportion of providers who reported discussing referral issues during routine management meetings. In addition, there was a significant improvement in the proportion of clients recorded as continuing on ART (over 6 months) at the endline, compared to baseline.

In the assessment, it was found that only half of the facilities had the minimum number of staff in the MCH/FP and CCC units necessary to support referrals; in addition, some facilities did not have adequate infrastructure to support referral of HIV positive FP clients to the care and treatment centres such as a directory, a register for documenting referral practices and client/patient tracer card. These inadequacies were discussed with the local health management teams, and have been rectified in some cases.

The study recommends that the Division of Reproductive Health, NASCOP and KEMSA and the provincial and district health management teams strengthen the supply of tools and commodities to health facilities in order to support the referrals of HIV+ FP clients to care and treatment centres. Update training on referral practices including the use of appropriate tools should be provided to all health providers working in any health facility in order to improve coverage and quality of care provided. Correct documentation and recordkeeping should be improved in order to keep track and monitor all referred cases in the facilities making and receiving referrals.

Given its potential role in improving referral practices within the RH and HIV settings, the study recommends that the Division of Reproductive Health, NASCOP and other units within the MOH such as the Health Management Information System support the provincial and district health management teams to scale up the use of the referral form developed under this project to other FP clinics within Central and other provinces. The tool could also be adopted for use with HIV+ clients in antenatal and postnatal services. 


\section{Abbreviations}

AIDS Acquired Immune Deficiency Syndrome

ARV

Antiretroviral

ART

Antiretroviral Therapy

BCS

Balanced Counseling Strategy

CCCs

Comprehensive Care Centers

CT (C\&T) Counseling and Testing (for HIV)

DASCO District AIDS Control Program

DHMT District Health Management Team

DH District Hospital

DRH Division of Reproductive Health

FP

Family Planning

GEP Guide to Essential Practice

HIV Human Immunodeficiency Virus

IUCD Intra-Uterine Contraceptive Device

KDHS Kenya Demographic and Health Survey

KEMSA Kenya Medical Supplies Agency

$\mathrm{MOH} \quad$ Ministry of Health

NASCOP National AIDS Control Program

PASCO Provincial AIDS and STD Control Officer

PGH Provincial General Hospital

PHMT Provincial Health Management Team

RH Reproductive Health

RTIs Reproductive Tract Infections

SDH Sub-District Hospital

STI Sexually Transmitted Infection

USAID United States Agency for International Development

WHO World Health Organization 


\section{Background and Problem Statement}

There has been growing interest in integrating family planning (FP) and HIV/ AIDS services in sub-Saharan Africa as a means of improving clients' access to both types of services, as well as injecting efficiency and cost-effectiveness in the provision of the services. ${ }^{1},{ }^{2}$ In Kenya, efforts to integrate RH services started after the 1994 International Conference on Population and Development (ICPD) held in Cairo that emphasized the need for integration. Initial efforts focused on integrating sexually transmitted infections (STIs) into Reproductive Health (RH). In recent years, there has been interest in integrating HIV into FP services (FHI 2006; Liambila et al 2008) and FP into HIV/AIDS services. The Government of Kenya has, however, developed a national RH and HIV/AIDS integration strategy which emphasizes the need to provide coordinated RH and HIV integrated services across the two programs.

Through the former FRONTIERS program, the Population Council worked with the Ministry of Health (MOH) to test the feasibility of two models for integrating counseling and testing (CT) for HIV into FP services. The project was implemented between November 2005 and March 2007. The two models involved 'testing' and 'referral' and have been described in detail elsewhere (Liambila et al 2009) In the "testing" model, FP providers were trained to offer CT services and post-test counseling during the same visit while in the "referral" model FP clients in need of CT services were referred to a specialized CT facility. Both models included client education on HIV prevention during FP visits. The intervention included the development of training materials, support for supplies and HIV test kits, and modification of registers to monitor CT services. Providers were trained to use the Balanced Counseling Strategy Plus (BCS+) toolkit, an adaptation of the Council's BCS tool for improving the quality of FP counseling ${ }^{3}$ modified for high HIV prevalence settings. The findings showed that: (1) integrating STI/HIV counseling and offering CT within FP services was feasible and acceptable to clients and providers; (2) quality of care improved significantly in both models; (3) counseling and testing for HIV increased significantly during FP consultations; and (4) between 50-75\% of the women offered an HIV test accepted it.

A major limitation of the previous project was that HIV-positive FP clients were not actively linked to care and treatment services, including antiretroviral treatment (ART), and screening and management of sexually transmitted infections (STIs). The health providers simply advised the clients to attend any

\footnotetext{
${ }^{1}$ Askew, Ian and Ndugga B. Maggwa. 2002. “Integration of STI Prevention and Management with Family Planning and Antenatal Care in sub-Saharan Africa - What More Do We Need to Know?" International Family Planning Perspectives 28(2):77-86.

2 Askew, Ian and Marge Berer. 2003. "The Contribution of Sexual and Reproductive Health Services to the Fight Against HIV/AIDS: A Review." Reproductive Health Matters 11(22):51-73. For more information: www. popcouncil.org/pdfs/frontiers/Manuals/BCS/BCS_Cards

${ }^{3}$ For more information: www.popcouncil.org/pdfs/frontiers/Manuals/BCS/BCS_Cards
} 
of the health facilities (mainly hospitals) that had comprehensive care centers (CCCs) for managing HIV/AIDS. Failure to link HIV-positive FP clients to treatment and care and STI services more systematically made it difficult to establish whether the clients visited the facilities or received the necessary services. In order to address this gap, Population Council and $\mathrm{MOH}$, through APHIAII Operations Research (OR) Project in Kenya, developed and tested a modified approach for linking HIV-positive FP clients to HIV care and treatment and STI services. The project was implemented in line with the national guidelines that encourage the integration of HIV testing with care and support-related HIV services for reproductive health $(\mathrm{RH})$ clients. It answers the following research question: "What is the most effective mechanism for linking family planning clients found to be HIV-positive to HIV care and treatment services?"

The project responds to the $\mathrm{MOH}$ efforts to achieve comprehensive integration of RH and HIV services. It also generates evidence on how institutional arrangements could be organized to reduce any barriers to linking HIVpositive FP clients to HIV and STI services. The project further contributes to the Government of Kenya (GOK) and United States Government (USG) goals of achieving healthier behaviors and increased use of high quality HIV/AIDS, RH/ FP and maternal and child health $(\mathrm{MCH})$ services. It also provides invaluable lessons on how provider-initiated testing and counseling (PITC) for HIV, which was launched in Kenya in 2008, can be effectively implemented ${ }^{4}$.

\section{Project Objectives}

The overall objective of the project was to develop a feasible and acceptable referral framework for linking family planning clients who test HIV-positive or know their HIV status to appropriate care and treatment services. Specifically, the project aimed to:

- Design and test a referral framework for linking HIV-positive FP clients to treatment and care in selected health facilities;

- Assess the acceptability of the proposed referral framework to providers; and

- Assess the effectiveness of the referral framework in terms of increasing the number of eligible HIV-positive FP clients received at HIV care and treatment services.

\footnotetext{
${ }^{4}$ Provider Initiated Counselling and Testing implies Routine offer of HIV testing in health care settings such as those attending STI services, ANC and other RH services including those attending TB clinic services among others (see WHO 2006 and 2007 and UNAIDS, 2007 references).
} 


\section{Project Design}

This was an operations research (OR) project involving pre- and post-intervention data collection without a control group. The project was implemented in Nyeri and Thika districts in selected sites where the original CT-FP pilot project was conducted. A total of six intervention sites were purposefully selected for inclusion in the study from the original 23 CT-FP project sites that were already offering

\begin{tabular}{|l|r|r|}
\hline \multicolumn{3}{|l|}{$\begin{array}{l}\text { Table 1: Workload data in FP clinics pre- and post- } \\
\text { intervention period (Source: Facility FP Registers) }\end{array}$} \\
\hline \multirow{4}{*}{} & \multicolumn{2}{|l|}{$\begin{array}{l}\text { Number of clients attending family } \\
\text { planning services }\end{array}$} \\
\cline { 2 - 3 } & $\begin{array}{l}\text { Baseline (August } \\
\text { 2009- March 2009) }\end{array}$ & $\begin{array}{l}\text { Endline (December } \\
\text { 2009- May 2010) }\end{array}$ \\
\hline Nyeri PGH & 2,803 & 2,753 \\
\hline Thika DH & 6,104 & 6,203 \\
\hline Gatundu DH & 3,623 & 4,229 \\
\hline Ruiru SDH & 2,624 & 2,367 \\
\hline Kirwara SDH & 1,847 & 1,708 \\
\hline Warazo SDH & 1,254 & 1,998 \\
\hline Total & 18,255 & 17,550 \\
\hline
\end{tabular}
integrated CT-FP services. To be included in the study, a facility had to have a comprehensive care center as part of its operations. The six facilities chosen were: Nyeri PGH and Warazo HC in Nyeri, and Thika DH, Gatundu DH, Ruiru SDH, and Kirwara SDH in Thika. The selected facilities were also implementing a prospective study on assessing the benefits of integrated HIV and RH services in Kenya, supported by the Gates Foundation through International Planned Parenthood Federation (IPPF) in collaboration with Population Council and the London School of Hygiene and Tropical Medicine. The following table summarizes the FP workload at the project sites during the project period:

The evaluation of the project was based on the following hypotheses:

- HIV-positive FP clients in intervention clinics are more likely to receive referral to ART services after the intervention than before.

- HIV-positive FP clients are more likely to visit the CCCs after the intervention has been introduced than before.

The study protocol was cleared by the Population Council's Institutional Review Board (IRB) in September 2009.

An algorithm (Fig.1) was developed during the design phase of the project, to guide health providers in counseling and testing clients wishing to know their HIV status. It was designed for use in facilities where the HIV test is carried out by the FP provider during the FP consultation, or at least on the same day and at the same facility. This algorithm does not apply to clients being referred to other facilities to be tested for HIV, since the person doing the HIV test is the one who would have responsibility for linking an HIV+ client to the CCC. 


\section{Intervention development, implementation and monitoring}

The interventions were conceptualized around a modified protocol for linking FP clients who test HIV-positive to care and treatment services summarized in Figure 1.

Figure 1: Modified Protocol for Testing Clients seeking FP Services

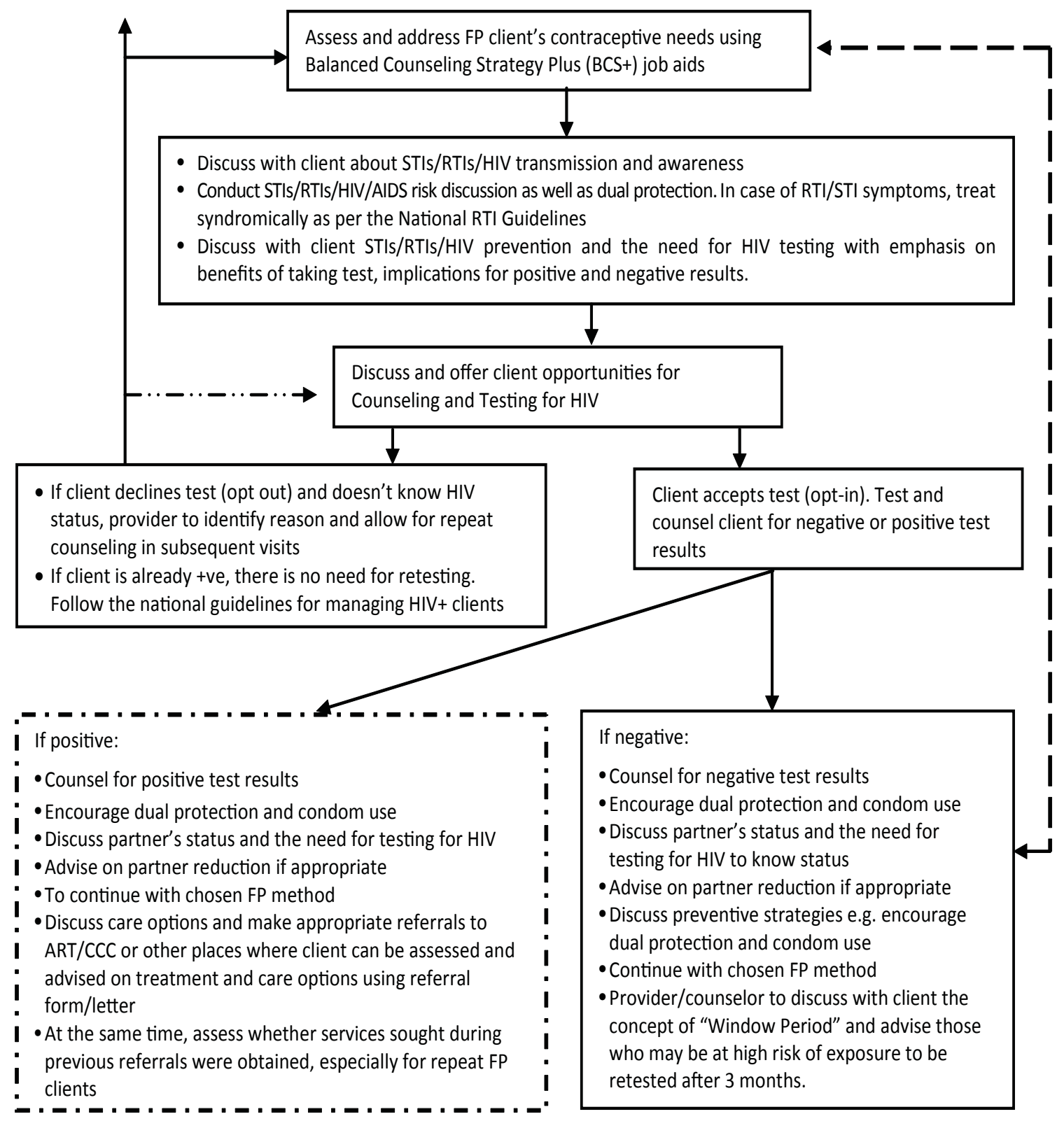


The interventions involved five activities implemented over a period of six months (November 2009 - May 2010). These included:

(i) Strengthening the referral system for HIV-positive FP clients

(ii) Review of existing training materials and job aids

(iii) Updating service providers with referral system information

(iv) Strengthening health facility supervision activities

(v) Strengthening health management information systems

\section{Activity 1: Strengthening referral system for HIV-positive FP clients}

A modified, strengthened referral system for HIV-positive FP clients was introduced in the six sites following the steps described in Box I.

\section{Box 1: Steps followed in conducting referrals of HIV positive FP clients}

1. Care options were discussed and appropriate referrals made using the referral form (See Annex 1) which was designed to capture information on client background characteristics, name of facilities conducting referrals and receiving clients, reasons for referral and appropriate comments.

2. Client told that the referral form is in triplicate. Original copy to be given to the client to take to the CCC (care and treatment centre of the receiving facility), duplicate copy is kept by the Provincial or District Reproductive Health Coordinator (project staff) and triplicate retained in the referral book at referring facility $/ \mathrm{clinic}^{5}$.

3. Once client arrives at the receiving facility, she/he is told to hand in the original form to the nursing officer in charge of CCC (or the officer on duty) who is expected to fill the referral forms, sign and file them in a designated referrals folder.

4. Client counseled on what to expect in CCCs including discussion on the types of investigations or assessments the client was likely to go through, such as CD4 count, testing and counseling on specific interventions recommended to the client, cost of treatment (especially if the facility is private) depending on her or his condition.

5. Client assured that the management of her or his condition is dependent on the outcome of the physical clinical assessment of her or his condition and laboratory evaluation of immunity using CD4 count assessments.

6. Client told that regardless of his/her state of immunity, everyone starts on Septrin (cotrimoxazole) to prevent opportunistic infections.

A directory of possible referral CCCs sites and other ART/STI services available in the vicinity of each study site was developed (Annex 1). The referral directory indicated the location, opening hours, fees and services provided and names of contact persons at the receiving sites. A total of 26 facilities with CCCs in Nyeri

\footnotetext{
${ }^{5}$ It is recommended that as referral practices become institutionalized, there will be no need for the triplicate copies. Duplicate copies will be sufficient. Original copy to be given to the client to take to the care and treatment centre of the receiving facility and the duplicate copy to be retained in the referral book in the facility initiating the referral.
} 
and 15 in Thika and the surrounding districts were included the directories. Meetings were held initially between the referring and receiving sites to discuss the referral modalities and ensure that the receiving sites recognize, respect and act upon the referral. The receiving sites also gave feedback on the outcomes of the referral, such as whether the client was registered for care or declined care. Monthly meetings were conducted throughout the study period to discuss challenges of the referral system and devise strategies for addressing them.

\section{Activity 2: Review of training materials and job aids}

Existing training and participant manuals for integrating CT into FP were reviewed and updated to include the component on screening for HIV and knowing the status and referrals. In addition, the Balanced Counseling Strategy (BCS+) tools (algorithm, cards and brochures) were revised to include information on STIs. The BCS-plus tools were subsequently translated into Kiswahili. The revision of the counseling cards was done in August 2009 jointly by the Population Council, Division of Reproductive Health (DRH), the National AIDS and STI Control Programme (NASCOP), and the Provincial Health Management Team (PHMT). It is worth noting that the BCS+ algorithm already includes a component on referral of clients. The revised materials were discussed and validated at a provincial-level meeting held in November 2009, which brought together district and facility stakeholders.

\section{Activity 3: Training service providers on updated tools}

Providers at the six sites were updated on the modified referral system (within the facility and to other facilities or from other facilities) as well as on the revised training materials and job aids. An example of the job aid on RTI/STI management in family planning care settings is found in Annex 2 of this report. A mentorship approach ${ }^{6}$ was used in updating the providers' knowledge and skills required to effectively link HIV-positive FP clients to ART/STI services. Mentors were selected from among health providers with experience in training. This approach encourages the providers to appreciate the fact that the roll out of HIV testing in Kenya has increased the proportion of women seeking FP services that want know their status, or who have been tested previously. During the update session, providers were told that FP clients who had tested negative in previous visits could also be re-tested depending on their history of exposure to HIV risk after the last test.

Twenty four (24) providers received on-site training using the mentorship approach from the six participating facilities. These included FP and HIV

\footnotetext{
${ }^{6}$ Mentorship is a system of practical training and consultation that fosters ongoing professional development to yield sustainable high-quality HIV/RH/FP services. Mentoring of less experienced individuals (mentees) by experienced staff (mentors) was an essential element of all health care learning in the pilot facilities. The need for mentorship arose to transform the existing didactic training, which has not always been successful in translating the acquired knowledge into practice, especially when conducted outside of the health facility settings. The mentorship approach sought to involve all health care workers providing $\mathrm{RH} / \mathrm{FP}$ services.
} 
providers as well as those working in the CCCs. Other professionals such as laboratory and pharmacy staff also received training on the job. The training focused on service integration, as well as an update on referral for HIV-positive FP clients. Proficiency in the use of the algorithm and job aids for integration and referral during post-test counseling among HIV-positive clients was also emphasized.

\section{Activity 4: Strengthening the referral system}

The fourth activity involved two major interventions: (1) strengthening the management information system; and (2) introducing a referral tool. FP registers at each facility provide the main source of information on the numbers of clients being referred to ART services. Although the FP registers have information on clients counseled and tested for HIV, there was no indication whether those who tested positive were referred to the CCCs. The project therefore trained providers to indicate whether the clients were referred to the CCCs in the remarks column in the FP registers.

In addition, the project developed a referral form (Annex 2) in collaboration with DRH and NASCOP. This was then pre-tested before sharing with service providers in the field. Each booklet had 50 copies of the referral forms in triplicate - the client was given the original copy to take to the receiving clinic/ site and the duplicate copy was retained in the facility making the referral. The triplicate copy was retained in the booklet. The receiving site kept a file of all the received referral forms.

\section{Activity 5: Strengthening of supervision activities and monitoring of interventions}

Monthly supervisory visits to facilities were conducted by members of Provincial Health Management Team (PHMT) and the District Health Management Team (DHMT) to monitor the intervention using a structured supervisory tool for the first six months of introducing the intervention. Information from the supervisory tool (Annex 3) and routine data collected from the facilities was analyzed and interpreted jointly with $\mathrm{MOH}$ officials at the district, provincial and national levels. Intensive supervision was undertaken in the initial six month to ensure early implementation of the intervention. Any problems that providers experienced in their clinic situation were dealt with immediately. Since some of the supervisors from the provincial level took part in the training of mentors, visits to the project sites were combined with routine supportive supervision visits in order to minimize duplication of effort and reduce supervision costs.

A team of staff drawn from DRH, NASCOP and Population Council conducted quarterly supervisory visits to the six implementation sites for the first two quarters of implementation. The visits focused on assessing referral practices for HIV positive FP clients from FP clinics to onsite or offsite CCC/ART units. The team also visited facilities that receive referral cases and discussed with 
the respective health facility management team's issues regarding how referred HIV positive FP clients are received and eventually enrolled into treatment and care programmes. Other activities during supervision involved checking on the availability of supplies and commodities in addition to monitoring the implementation of the mentorship programme.

During supervision, additional information was sought on the following issues:

- Number and frequency of formal meetings held at the facility level during which facility management issues are discussed, including referral of HIV positive FP clients and how they are linked to treatment and care services in CCCs/ART units.

- The extent to which project supervision is integrated in the overall institutional supervision activities. Integration of project activities into the overall institutional supervision activities made it possible for all the staff in the facility $\mathrm{MCH} / \mathrm{FP}$ and the CCCs to get involved in reviewing findings pertaining to project supervision more critically and in taking action to address the identified gaps using available resources.

\section{Project evaluation}

Data collection involved facility assessment, provider interviews, and record reviews.

Facility assessment: A systematic inventory/audit, including interviews with staff in charge of clinic, was undertaken at each of the six study facilities (Table 2) to determine clinic readiness to link HIV-positive FP clients to ART. The assessment focused on staffing and infrastructure - availability of CCC, equipment and supplies. Two research assistants spent half a day at each clinic completing the inventory.

Provider interviews: A total of 24 providers (Table 2) both at baseline and endline were interviewed (four FP and CCC service providers per facility). These included seven enrolled nurses, 14 registered nurses, and three clinical officers at both baseline and endline. Information was collected on provider training, knowledge of counseling for referral, and experience with implementing referral guidelines.

Record review within the CCC and in FP clinics: At baseline and endline, trained research assistants extracted records of clients referred to CCC from FP clinic using a standardized checklist, that was based on the national guidelines for managing HIV positive clients (for treatment and care options). Specifically, the following information was extracted from the records: (1) source of referral (2) whether client went through pre- ART counseling; (3) appropriate attachments and other documents/records that constitute standard care for HIV positive patients, and whether the records were filled correctly; and (4) whether all the necessary procedures such as investigations and care were received and whether these 
were documented appropriately. At baseline a total of $454 \mathrm{HIV}$ positive FP client records were reviewed for the period August-March 2009 (six months preceding the interventions) in the six health facilities. Post-intervention measurements took place in June 2010, during which a total of 487 HIV positive FP client records were reviewed at the CCC for the period December 2009 to May 2010 (the six months intervention phase). Table 2 provides a summary of the data collected in the research.

Table 2: Sample sizes achieved by type of survey conducted at baseline and endline by facility

\begin{tabular}{|l|l|c|c|c|c|c|c|c|}
\hline $\begin{array}{l}\text { Type of survey } \\
\text { conducted }\end{array}$ & $\begin{array}{l}\text { Timing } \\
\text { /Phase }\end{array}$ & $\begin{array}{l}\text { Nyeri } \\
\text { PGH }\end{array}$ & $\begin{array}{l}\text { Thika } \\
\text { DH }\end{array}$ & $\begin{array}{l}\text { Gatundu } \\
\text { DH }\end{array}$ & $\begin{array}{l}\text { Ruiru } \\
\text { SDH }\end{array}$ & $\begin{array}{l}\text { Kirwara } \\
\text { SDH }\end{array}$ & $\begin{array}{l}\text { Warazo } \\
\text { SDH }\end{array}$ & $\begin{array}{l}\text { Total } \\
\text { Sample }\end{array}$ \\
\hline $\begin{array}{l}\text { FP Client Records } \\
\text { Review in CCCs }\end{array}$ & Baseline & 120 & 120 & 120 & 37 & 36 & 21 & 454 \\
\cline { 2 - 10 } & Endline & 87 & 150 & 86 & 99 & 37 & 28 & 487 \\
\hline $\begin{array}{l}\text { Provider } \\
\text { Interviews }\end{array}$ & Baseline & 4 & 4 & 4 & 4 & 4 & 4 & 24 \\
\cline { 2 - 10 } & Endline & 4 & 4 & 4 & 4 & 4 & 4 & 24 \\
\hline $\begin{array}{l}\text { Facility } \\
\text { Assessment }\end{array}$ & Baseline & 1 & 1 & 1 & 1 & 1 & 1 & 6 \\
\cline { 2 - 10 } & Endline & 1 & 1 & 1 & 1 & 1 & 1 & 6 \\
\hline
\end{tabular}

\section{Data analysis}

Analysis involved simple descriptive statistics (frequencies, percentages, and scores) with significant tests (of means and proportions) to determine if there are any significance differences in the indicators of interest between before and after time-periods.

\section{Findings}

\section{Characteristics of clients whose records were reviewed}

At both baseline and endline, the mean and median age of clients from the records was 33 years with the oldest client being 60 years and the youngest 18 years old. Repeat and new FP clients constituted $97 \%$ and 3\% of the total clients respectively at baseline while at endline repeat clients constituted $94 \%$ and new clients $6 \%$. Majority of clients were married and in monogamous relationships $(63 \%$ at both baseline and endline). Within the CCCs, over $97 \%$ of the records had CD4 values with $61 \%$ of the values being below 350 while $39 \%$ were above this cutoff range in both baseline and endline surveys.

The following sections summarize the findings in the three key areas of the assessment: facility preparedness to support referral of HIV-positive clients to treatment and care services; acceptability of referral among providers and clients, and the effectiveness of the referral framework in terms of linking HIV-positive FP clients to treatment and care services. 


\section{Facility preparedness}

Table 3 presents the distribution of the key indicators used in this study to assess facility preparedness to support referral services for HIV-positive FP clients in the $\mathrm{MCH} / \mathrm{FP}$ and $\mathrm{CCC}$ units of the participating facilities at baseline. In addition to staffing levels, facility preparedness was also assessed through the following factors:

- availability of registers and cards: 6 items (partner notification card, client card, FP, pre-ART, ART, and antiretroviral drugs (ARV) registers)

- availability of FP commodities: 6 items (combined oral pill, depo provera, implants, male condoms, and female condoms)

- availability of STI drugs: 5 items (drugs for management of urethral discharge, genital ulcers, ophthalmia neonatorum, virginal discharge/ pruritus, and lower abdominal pain)

- availability of HIV test kits and reagents: 6 items (Determine, Bioline, Unigold, laboratory reagents for urinalysis, full haemogram reagents, and infection prevention items)

- availability of infrastructure: 6 items (availability of directory for use in referring clients to the CCCs and other STI services, referral guidelines; a register for documenting referral practices; client/patient tracer card; mechanisms for reviewing referral decisions/ arrangements e.g. through monthly meetings; and feedback mechanisms between referring and receiving facilities).

In regard to staffing in an $\mathrm{MCH}$ unit, the $\mathrm{MOH}$ guidelines recommend a minimum of four nurses, two Clinical Officers, and one pharmacist/pharmaceutical technologist at Level Three facilities (such as Ruiru Sub-District Hospital, Kirwara Sub-District Hospital, and Warazo HC). The recommendation for Level Four facilities such as Gatundu District Hospital are six nurses, two clinical officers, and three pharmacists/ pharmaceutical technologists while Level Five facilities should have a minimum of 12 nurses, four Clinical Officers, and six pharmacists/ pharmaceutical technologists. In addition, the minimum number of medical officers recommended for Levels Four and Five facilities are six and 15 respectively. 
Table 3: Distribution of key indicators of facility preparedness to support referral of HIV-positive family planning clients at baseline at $\mathrm{MCH} / \mathrm{FP}$ and $\mathrm{CCC}$ units

\begin{tabular}{|l|c|c|c|c|c|c|c|}
\hline Indicators & $\begin{array}{l}\text { Thika } \\
\text { DH }\end{array}$ & $\begin{array}{l}\text { Ruiru } \\
\text { SDH }\end{array}$ & $\begin{array}{l}\text { Gatundu } \\
\text { DH }\end{array}$ & $\begin{array}{l}\text { Nyeri } \\
\text { PGH }\end{array}$ & $\begin{array}{l}\text { Kirwara } \\
\text { SDH }\end{array}$ & $\begin{array}{l}\text { Warazo } \\
\text { HC }\end{array}$ & Total \\
\hline Staff availability (number) & & & & & & & \\
\hline \multicolumn{1}{|c|}{ Medical officers } & 23 & 0 & 1 & 4 & 0 & 0 & 10 \\
\hline Nurses & 3 & 1 & 2 & 3 & 2 & 0 & 11 \\
\hline Clinical officers & 3 & 0 & 0 & 0 & 0 & 0 & 3 \\
\hline Pharmacists/PT & 5 & 6 & 5 & 5 & 4 & 6 & $31 / 36$ \\
\hline $\begin{array}{l}\text { Availability of registers and } \\
\text { cards (score on 6 items) }\end{array}$ & 3 & 4 & 3 & 4 & 4 & 3 & $21 / 36$ \\
\hline $\begin{array}{l}\text { Availability of key FP } \\
\text { commodities (score on 6 items) }\end{array}$ & 5 & 2 & 2 & 0 & 5 & 2 & $16 / 30$ \\
\hline $\begin{array}{l}\text { Availability of STI drugs (score } \\
\text { on 5 items) }\end{array}$ & 6 & 6 & 5 & 2 & 6 & 4 & $29 / 36$ \\
\hline $\begin{array}{l}\text { Availability of HIV test kits and } \\
\text { reagents (score on 6 items) }\end{array}$ & 1 & 4 & 1 & 3 & 0 & 0 & $9 / 36$ \\
\hline $\begin{array}{l}\text { Availability of infrastructure } \\
\text { (score on 6 items) }\end{array}$ & 1 & 5 & 12 & 4 & 2 & 52 \\
\hline
\end{tabular}

Note: PGH: Provincial General Hospital; DH: District Hospital; SDH: Sub-District Hospital; HC: Health Centre; FP: family planning; MCH: maternal and child health; CCC: comprehensive care center; STIs: sexually transmitted infections; PT: pharmaceutical technologist

Staffing: The results show that only three of the six facilities had the minimum number of staff necessary to support referral and linkage of HIV-positive FP clients to treatment and care (Table 3). The exceptions were Nyeri PGH, Gatundu DH, Warazo HC and Kirwara SDH which did not have any pharmacist/pharmaceutical technologist in the $\mathrm{MCH} / \mathrm{FP} / \mathrm{CCC}$ units. Warazo HC did not have any pharmacist/ pharmaceutical technologist in the entire facility. Although Nyeri PGH and Gatundu DH had seven and six pharmacists/pharmaceutical technologists respectively in other units, there were none in the $\mathrm{MCH} / \mathrm{FP}$ and $\mathrm{CCC}$ units. In Warazo HC, therefore, providers were likely to refer HIV-positive FP clients for drugs to other facilities while in Nyeri PGH and Gatundu DH, such clients were likely to be referred to other units within the same facility. There were no changes in the staffing levels by endline.

Registers and client cards: Only two of the six facilities at baseline had all the essential registers and tracer/client cards to support referral of HIV-positive clients to treatment and care at baseline (Table 3). It is interesting to note that lower level facilities like Ruiru SDH and Warazo Sub-District Hospitals had all the registers and cards compared to higher level facilities. Nyeri PGH, Thika and Gatundu DH did not, for instance, have partner notification cards. This information was shared with the facility in-charges and the DHMTs in the two districts and by endline, Thika and Gatundu DH had obtained the cards from NASCOP. The situation remained the same in the other facilities. 
Availability of key FP commodities: None of the facilities had all the six FP commodities (combined oral pill, depo provera, implants, male condoms, and female condoms) at both baseline and endline, and half had only four of the commodities. Female condoms and implants were the least available FP methods; female condoms were available only in Kirwara SDH only while only Nyeri PGH and Ruiru SDH had implants.

Availability of STI drugs: Only two facilities (Thika DH and Kirwara SDH) had all the required STI drugs in the $\mathrm{MCH} / \mathrm{FP}$ and CCC units at baseline and endline. At Nyeri PGH, the drugs were available at the pharmacy, but none at the MCH/FP and CCC units (Table 2). In addition, only half of the facilities had all the necessary $\mathrm{HIV}$ test kits and reagents in the MCH/FP and CCC units at baseline, and by endline, only Nyeri PGH had all the relevant test kits and reagents.

Availability of necessary infrastructure: Facility preparedness was also assessed on the availability of the infrastructure needed to carry out referral and other activities for linking HIV-positive FP clients to care and treatment. This included the following six items: directory for use in making referrals; referral guidelines; a register for documenting referral practices; client/patient tracer card; the existence of mechanisms for reviewing referral decisions/ arrangements e.g. through monthly meetings; and feedback mechanisms between referring and receiving facilities. At baseline, only two of the facilities (Nyeri PGH and Ruiru SDH) scored three or higher on the indicators of infrastructure availability (Table 3). This, however, improved during the project period as four of the six facilities (Thika DH, Ruiru SDH, Kirwara SDH, and Warazo HC) scored five or higher on these indicators at the endline.

The improvement in the indicators of infrastructure availability at the endline could be attributed to interventions such as the development of the referral directory and referral forms as well as strengthening mechanisms for reviewing referral decisions/ arrangements.

\section{Acceptability of referral by providers}

Acceptability by providers of referral of HIV-positive FP clients to treatment and care is measured by two indicators - the proportion of providers reporting having a directory of facilities and their contact details where HIV-positive clients could be referred; and the proportion of providers reporting discussing referral issues during routine management meetings. Between

\begin{tabular}{|c|c|c|}
\hline Indicator & $\begin{array}{l}\text { Baseline } \\
(\mathrm{N}=24)\end{array}$ & \begin{tabular}{|l} 
Endline \\
$(\mathrm{N}=24)$
\end{tabular} \\
\hline $\begin{array}{l}\text { Proportion of providers using a } \\
\text { directory for referral (\%) }\end{array}$ & $8^{a}$ & $58^{* *}$ \\
\hline $\begin{array}{l}\text { Proportion of providers } \\
\text { discussing referral of HIV- } \\
\text { positive FP clients (\%) }\end{array}$ & 71 & $96^{*}$ \\
\hline
\end{tabular}
baseline and endline, there were 
significant increases in the proportions of providers reporting having a directory for use for referral $(\mathrm{p}<0.01)$ and discussing referral of HIV-positive FP clients during routine management meetings $(\mathrm{p}<0.05$, Table 4$)$.

\section{Quality of care measures}

A review of quality of care indicators showed that there was a significant improvement at endline in the provision of ARVs, HAART and proper documentation of records, compared to the situation at the baseline. The records show significant improvement in the proportion of clients recorded as continuing with HAART (over 6 months) at endline, compared to baseline. These measures are summarized in Table 5 below.

Table 5: Distribution of key indicators of quality of care within the CCCs (\%)

\begin{tabular}{|l|r|r|}
\hline Indicators & $\begin{array}{r}\text { Baseline } \\
(\mathrm{N}=454) \%\end{array}$ & $\begin{array}{l}\text { Endline } \\
\text { (N=487)\% }\end{array}$ \\
\hline $\begin{array}{l}\text { Proportion of records showing WHO clinical staging for HIV/AIDS7 had } \\
\text { been done }\end{array}$ & 90 & 89 \\
\hline Proportion of records showing CD4+ values & 97 & 98 \\
\hline Proportion of records showing whether clients are on ARVs & 8 & $49 *$ \\
\hline $\begin{array}{l}\text { Proportion of records showing that the client had just started HAART } \\
\text { (within 6 months) }\end{array}$ & 15 & $25^{*}$ \\
\hline Proportion of records that had the necessary documents filled correctly & $28^{*}$ \\
\hline
\end{tabular}

\section{Effectiveness of referral}

Client records provide information on effectiveness of referral of HIV-positive FP clients to treatment and care. Initially, there was no referral of HIV-positive FP clients to CCCs. However, during the intervention period, most of the HIV-positive FP clients received at CCCs $(93 \%)$ were from within the MCH/FP unit of the same facility indicating that the referral system was effective (Table 6). The facilities also received HIV+ve FP clients from other facilities except Kirwara SDH and Warazo health centre.

\footnotetext{
${ }^{7}$ WHO staging system is a simplified AIDS staging system that is based on 4 groups of clinical conditions that have prognostic significance and therefore constitute stages, plus an assessment of physical activity performance expressed as a 4-point score; Pts are classified according to the highest stage recorded for either clinical condition or physical activity. Patients are asymptomatic; mildly symptomatic; moderately symptomatic; severely symptomatic. Clinical Stage 1 (asymptomatic, normal activity), Clinical Stage 2 (Unintentional weight loss $<10 \%$ body weight), Clinical Stage 3(Unintentional weight loss $>10 \%$ body weight, Chronic diarrhea $>1$ month, prolonged fever $>1$ month (constant or intermittent), Clinical Stage 4 (HIV wasting syndrome, severe opportunistic infection and severely ill).
} 
Table 6: Distribution of HIV-positive family planning clients referred and received at comprehensive care centers from within the facility, January-June $\mathbf{2 0 1 0}$

\begin{tabular}{|l|l|l|l|l|}
\hline Health facility & $\begin{array}{l}\text { Number } \\
\text { of HIV+ FP } \\
\text { clients }\end{array}$ & $\begin{array}{l}\text { Number of HIV+ } \\
\text { FP clients received } \\
\text { at CCC from within } \\
\text { facility }\end{array}$ & $\begin{array}{l}\text { Proportion of } \\
\text { HIV+ve FP clients } \\
\text { received at CCC from } \\
\text { within facility) }\end{array}$ & $\begin{array}{l}\text { Number of HIV+ve } \\
\text { FP clients received } \\
\text { at CCC from other } \\
\text { facilities }\end{array}$ \\
\hline Nyeri PGH & 3 & 3 & 100 & 10 \\
\hline Thika DH & 9 & 9 & 100 & 9 \\
\hline Gatundu DH & 10 & 9 & 90 & 8 \\
\hline Ruiru SDH & 40 & 39 & 98 & 3 \\
\hline Kirwara SDH & 4 & 2 & 50 & 0 \\
\hline Warazo HC & 5 & 3 & 60 & 0 \\
\hline Total & 71 & 66 & 93 & 30 \\
\hline
\end{tabular}

PGH: Provincial General Hospital; DH: District Hospital; SDH: Sub-District Hospital; FP: family planning; CCC: comprehensive care center.

\section{Discussions, Conclusions and Recommendations}

The objective of this project was to develop a feasible, acceptable and effective referral framework for linking family planning clients who test HIV-positive to appropriate care and treatment services. The evaluation strategy included assessing facility preparedness to support referral, provider acceptance, and effectiveness of the referral framework. Although only half of the facilities had the minimum number of staff in the $\mathrm{MCH} / \mathrm{FP}$ and CCC units necessary to support referral, other facilities had, in fact, adequate cadres of staff in other departments. The MCH/FP and CCC units could therefore easily benefit from internal reallocation of staff without necessarily bringing in new staff from elsewhere in such facilities.

Most facilities scored poorly at baseline in the availability of the necessary infrastructure to support referral including a directory for use in referring clients to the CCCs and other STI services, referral guidelines, a register for documenting referral practices, and client/patient tracer card. Although some of the gaps were addressed by the relevant facilities and DHMTs during the project period, such poor indicators could be due to the limitations in the health care system including inadequate supply system, as most of these are available in the $\mathrm{MOH}$ system.

As pointed out in the earlier sections of this report, the algorithm for the study was designed for use in facilities where the HIV test is carried out by the FP provider during the FP consultation, or at least on the same day and at the same facility. The algorithm does not apply to clients being referred to other facilities to be tested for $\mathrm{HIV}$, since the person doing the HIV test is the one who would have responsibility for linking an HIV+ client to care and treatment. Following the launch of the 
provider initiated testing and counseling (PITC) policy by the Government of Kenya (GOK 2008) ${ }^{8}$, the proportion of clients attending FP/RH clinics who know their status has increased tremendously. In addition, there are significant proportions of clients who either prefer to be referred to other health facilities to be tested for HIV or to access care and treatment in facilities of their choice. These scenarios bring out the need to develop or modify the current algorithm to enable health providers to address the needs of different FP/RH clients seeking referral to other health facilities and those willing to be counseled and tested for HIV on site.

Despite the noted gaps in facility preparedness, the project interventions led to improved provider acceptance of referral practices. Specifically, significant increases occurred in the proportions of providers reporting having a directory for use for referral and discussing referral of HIV-positive FP clients during routine management meetings between baseline and endline. Moreover, the referral system was also found to be effective as most of the HIV-positive FP clients received at CCCs were from within the $\mathrm{MCH} / \mathrm{FP}$ unit of the same facility. The study therefore shows that referral and linking of HIV-positive FP clients to treatment and care is acceptable and effective even with minimal level of preparedness on the part of the facilities.

The following recommendations can be made, in view of these findings:

- Strengthening the supply chain for tools and commodities: Some facilities did not have the necessary resources to support referral and linkage of HIVpositive clients to treatment and care at baseline. By endline, however, most of the required resources were available at the facilities. This suggests the need to strengthen the supply of the necessary tools (e.g. referral forms, cards) and commodities (FP, HIV test kits) for the referral system to be more effective.

- Facility-wide provider training/updates on referral: Although the proportion of providers using the referral directory increased significantly, about $40 \%$ were still not using the directory at endline. Either most did not know that the directories exist, perhaps due to staff rotation or they referred clients to the same facility without providing information on other available options. This suggests the need for facility-wide updates/training so that more health workers within the facility are aware of the directory and the available options for clients.

- Scaling up the use of the referral form: The project showed that the use of the referral form can be introduced in facilities with minimal infrastructure. It also does not require intensive provider training/update. This suggests that its use can easily be scaled up to other facilities in the country. In addition, the form can easily be adopted in other departments including antenatal and post-natal care clinics as a tool for referring HIV-positive clients to appropriate care and treatment.

\footnotetext{
${ }^{8}$ Provider Initiated Counseling and Testing implies Routine offer of HIV testing in health care settings such as those attending STI services, ANC and other RH services including those attending TB clinic services among others.
} 
- Improving recordkeeping and documentation: Health providers need to be updated on the importance and correct procedure of filling in client records especially at CCCs, to improve the current recordkeeping.

- Modification of the testing and counseling algorithm: There is need to modify the current algorithm to enable health providers to address the needs of different $\mathrm{FP} / \mathrm{RH}$ clients seeking referral to other health facilities and those willing to be counseled and tested for HIV on site.

\section{Study Limitations}

The study had a number of limitations. First, the number and types of participating health facilities were different and might have affected the referral mechanism. Two of the facilities (Thika DH and Nyeri PGH) are Level 5 referral health facilities while Gatundu DH is Level 4. The other facilities - Ruiru SDH, Kirwara SDH, and Warazo HC - are Level 3 facilities, which essentially function as health centers. Therefore, referrals at Levels 4 and 5 facilities are likely to be internal, while the lower level ones are likely to refer to other facilities. This has implications for client tracing and defaulting. Secondly, in Nyeri, clients from Warazo HC are likely not to take up referrals to Nyeri PGH because of distance and cost of transport. 


\section{References}

World Health Organization (WHO)/Joint United Nations Programme on HIV/AIDS. WHO and UNAIDS Secretariat Statement on HIV Testing and Counseling. Geneva: WHO/UNAIDS; 2006.

World Health Organization (WHO)/Joint United Nations Programme on HIV/AIDS (UNAIDS). Guidance on Provider Initiated HIV Testing and Counseling in Health Facilities. Geneva: WHO/UNAIDS; 2007

UNAIDS Reference Group on HIV and Human Rights. Seventh Meeting Issue Paper: provider-initiated testing and counseling in health facilities; 12-14 February 2007.

Family Health International (FHI). 2006. Integrating Family Planning into HIV Voluntary Counseling and Testing Services in Kenya: Progress to Date and Lessons Learned. Research Triangle Park, USA: FHI

Liambila, W., I. Askew, J. Mwangi, R. Ayisi, J. Kibaru, S. Mullick. 2009. “Feasibility and effectiveness of integrating provider initiated testing and counseling within family planning services in Kenya." AIDS 23(Suppl. 1):S115-S121.

National AIDS and STI Control Programme, Ministry of Public Health and Sanitation, Kenya. Guidelines for HIV Testing and Counseling and Kenya. Nairobi: NASCOP; 2008.

Liambia, W., I. Askew, R. Ayisi, M. Gathitu, J. Mwangi, R. Homan, et al. 2008. Feasibility, acceptability, effect and cost of integrating counseling and testing for HIV within family planning services in Kenya. Frontiers Final Report., Washington, D.C., Population Council.

Republic of Kenya. 2009. National Reproductive Health and HIV and AIDS Integration Strategy. Nairobi: NASCOP and DRH. 


\section{Annex 1: Directory of health facilities providing care and treatment}

including STIs, further investigations and other services to the referred clients or patients

\begin{tabular}{|l|l|l|l|l|l|l|}
\hline & $\begin{array}{l}\text { Facility } \\
\text { Name }\end{array}$ & $\begin{array}{l}\text { Ownership: } \\
\text { Enter code:1=GOK, } \\
\text { 2=Mission/NGO, } \\
\text { 3=Private,4=Other) }\end{array}$ & Location & $\begin{array}{l}\text { Opening } \\
\text { Hours }\end{array}$ & $\begin{array}{l}\text { Services } \\
\text { Offered** }\end{array}$ & $\begin{array}{l}\text { Telephone No. of } \\
\text { Facility/ Officer-in } \\
\text { charge }\end{array}$ \\
\hline 1 & & & & & & \\
\hline 2 & & & & & & \\
\hline 3 & & & & & & \\
\hline 4 & & & & & & \\
\hline 5 & & & & & & \\
\hline 6 & & & & & & \\
\hline 7 & & & & & & \\
\hline
\end{tabular}

** Insert appropriate code1= FP provision, 2=STI counseling/treatment, 3= HIV post-test counseling, $4=\mathrm{HIV}$ care/ARV, 5= TB Screening/Diagnosis or Treatment, 6=Other Ols, 7= Psycho-social Support, 8=CD 4 Count, 9= Blood for full haemogram/Count, 10= Others (Specify $--)$. 


\section{Annex 2: Referral Form}

Instructions for filling form: Fill in triplicate. Give original copy to client and retain duplicate at referring facility/clinic. The referring and receiving staff should insert their names, designation and date in the appropriate space provided. All completed forms should be handed to the Nursing officer in -charge of CCC or MCH/FP for filing.

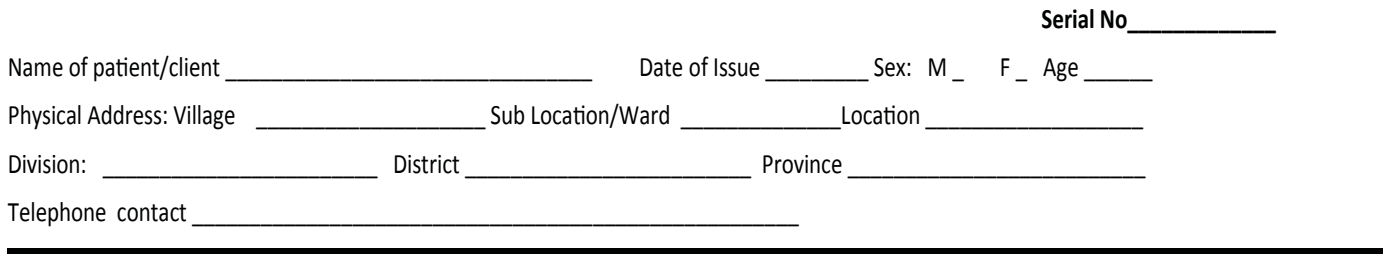

A) REFERRALS WITHIN FACILITY

Referred from: (Clinic/Unit) Referred to: (Clinic/Unit)

\section{B) REFERRALS FROM OUTSIDE FACILITY}

Referred from: (Health facility/Clinic)

Referred to: (Health facility/Clinic

\begin{tabular}{|c|c|}
\hline What is client seen for? & What is client referred for? \\
\hline$\square$ FP counseling & $\square$ FP counseling \\
\hline$\square$ FP provision & $\square$ FP provision \\
\hline$\square$ STI counseling/treatment & $\square$ STI counseling/treatment \\
\hline$\square$ HIV counseling & $\square$ HIV counseling \\
\hline$\square$ HIV testing (blood test) & $\square$ HIV testing (blood test) \\
\hline$\square$ HIV care (pre ART not on ARV) & $\square$ HIV care (pre ART not on ARV) \\
\hline$\square$ HIV care (ART on ARV) & $\square$ HIV care (ART on ARV) \\
\hline$\square$ TB Screening/Diagnosis & $\square$ TB Screening/Diagnosis \\
\hline$\square$ TB treatment & $\square$ TB Treatment \\
\hline$\square$ Other Ol & $\square$ Other Ol \\
\hline$\square \mathrm{CD} 4$ Count & $\square \mathrm{CD} 4$ Count \\
\hline$\square$ Psycho-socio Support & $\square$ Psycho-socio Support \\
\hline$\square$ ANC/PMTCT & $\square$ ANC/PMTCT \\
\hline$\square$ PNC for mother & $\square$ PNC for mother \\
\hline$\square$ Child (growth monitoring ) & $\square$ Child (growth monitoring ) \\
\hline$\square$ Child immunization & $\square$ Child immunization \\
\hline$\square$ Cervical screening & $\square$ Cervical screening \\
\hline$\square$ Other (specify): & $\square$ Other (specify): \\
\hline
\end{tabular}

Comments

Referred by (Name of staff) Designation Phone No- 


\section{Annex 3: Supervisory Tool}

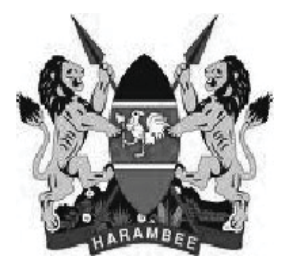

Ministries of Public Health \& Sanitation, and Medical services

Integrating RH/HIV Services within PNC/FP \& CCC settings and linking HIV Positive clients to treatment and care

\section{Facilitative Supervision Tool}

\section{BACKGROUND INFORMATION}

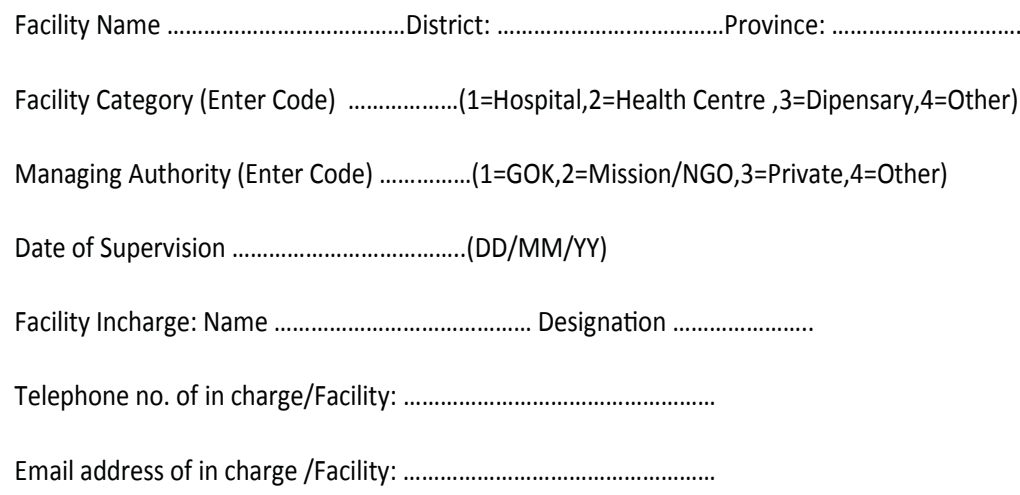

2. SERVICES OFFERED IN THE FACILITY (Tick as appropriate)

$\square$ FP counseling

$\square$ TB Screening/Diagnosis

FP provision

$\square$ TB treatment

STI counseling/treatment

$\square$ Other OI

HIV counseling

CD 4 Count

HIV testing (blood test)

Psycho-socio Support

HIV care (pre ART not on ARV)

ANC/PMTCT

HIV care (ART on ARV)

PNC for mother

Child (growth monitoring)

Cervical screening

Child immunization

Other (specify):

2. (b) Comment on the services that you were previously offering but have not been able to offer in last one month(For each service mentioned, note and explore the underlying reasons) 
Staffing, indicate the total number of staff by cadre in the appropriate box

\begin{tabular}{|l|l|l|l|l|}
\hline CADRE & \multicolumn{1}{|c|}{ Total No. of staffs at facility } & NO. in MCH/FP & No in CCC \\
\hline Doctors: Obs/Gyn & \multicolumn{1}{|c|}{ M } & & \\
\hline Pediatricians & & & & \\
\hline Others (Medical officers, & & & & \\
\hline Clinical Officers: RCOs & & & & \\
\hline RH RCOs & & & & \\
\hline Nurses: Registered & & & & \\
\hline Enrolled & & & & \\
\hline Pharmacists/ Tech & & & & \\
\hline PHTs/ PHOs & & & & \\
\hline Nutritionists & & & & \\
\hline Others & & & & \\
\hline
\end{tabular}

4.

STAFFING \& TRAINING UPDATES IN THE LAST 24 MONTHS $^{1}$

\begin{tabular}{|l|l|l|l|l|}
\hline Updates / Training & No.Trained & Updates / Training & No.Trained & Others /Comments \\
\hline EOC & & PMTCT & & \\
\hline Newborn health & & IMAI & & \\
\hline PAC & & CTS & & \\
\hline HIV/ STI/RTI /FP integration & & ART PAED/ ADULT & & \\
\hline CTU & & POSTNATAL CARE & & \\
\hline ASRH & & VIA/VILI & & \\
\hline Comprehensive RH training & & IMCI & & \\
\hline Post Rape care & & FANC/MIP/TB & & \\
\hline Logistic management & & Facilitative Supervision & & \\
\hline
\end{tabular}

5. CAPACITY BUILDING/TRAINING AND UPDATES

a) Comment on availability of a training data base in the facility

b) How does the training plan promote integration of RH/HIV activities?( Check for training schedules for $\mathrm{RH} / \mathrm{HIV}$ integration)

Comment on the following issues

-Availability of a training team

-Planning process for training

-Process of selecting participants/facilitators

-Training materials /resources, equipment, supplies and venues

-Training approaches e.g OJT,CMEs/CPD and other fora

-Training/learning methodologies/aids

-Evaluation of trainings e.g Knowledge and skills assessment(tools)

-Post training follow ups (Enquire on tools being used)

What are the main challenges affecting training and how have they is addressed?

1 *EOC - Essential Obstetric Care; PAC - Post + Abortion Care: CTS - Clinical Training Skills: FP - Family Planning; ASRH - Adolescent Reproductive Health

FANC - Focused Antenatal Care: MIP - Malaria in Pregnancy: IMCI-integrated management of childhood illnesses; VIA/VILI - Visual inspection with acid / 
6. AVAILABILITY OF TOOLS IN THE FACILITY

Are the following tools available and in use in the facility? Place tick $\mathbf{v}$ as appropriate

\begin{tabular}{|l|l|l|l|}
\hline Tools available & In Use & Not in use & Explanation if tool (s) Not in use \\
\hline OPD Register & & & \\
\hline Partner notification card & & & \\
\hline Monthly summary Report Forms & & & \\
\hline Job aids(RH/HIV) & & & \\
\hline FP Register & & & \\
\hline PNC Register & & & \\
\hline Child welfare Register & & & \\
\hline Maternity/Delivery Register & & & \\
\hline ANC/PMTCT Register & & & \\
\hline ART Register & & & \\
\hline ARV Registers & & & \\
\hline Daily Activity Registers:(FP, PNC, Test kits, CCC) & & & \\
\hline Client Cards:(FP,PNC,CCC) & & & \\
\hline Other specify)........................... & & & \\
\hline
\end{tabular}

\section{STATUS OF COMMODITIES DURING THE MONTH}

Did the facility experience stock outs of the following RH commodities for more than 7 days during the month? (Place a tick in the appropriate "yes" or "no" column for each of the items listed). If FP commodities were not available, discuss with the facility staff and outline the reasons in the appropriate row in the table.

i) RH Commodities

\begin{tabular}{|l|l|l|l|l|}
\hline \multicolumn{2}{|l|}{ Commodity stock outs for more than 7 days } & Y & N & Reasons for stock outs( if response was “Yes" \\
\hline a) & Combined pill (COCP) & & & \\
\hline b) & IUCD & & & \\
\hline c) & Depo provera & & & \\
\hline d) & Implants (Eg Jadelle, Implanon) & & & \\
\hline e) & Male Condoms & & & \\
\hline f) & Female condoms & & & \\
\hline g) & Microlut & & & \\
\hline h) & Others (specify) & & & \\
\hline
\end{tabular}

\section{ii) STI/HIV commodities}

(i) Did the facility experience stock outs of the RH/HIV drugs/supplies for more than 7 days during the month? (Place a tick in the appropriate "yes" or "no" Columns for each of the items listed).

\begin{tabular}{|l|l|l|l|l|l|}
\hline \multicolumn{2}{|l|}{ Drugs/Supplies stock outs for more than 7 days } & Y & N & $\begin{array}{l}\text { If yes list the } \\
\text { item }\end{array}$ & $\begin{array}{l}\text { Reasons for stock outs \& } \\
\text { action taken }\end{array}$ \\
\hline a) & Drugs for Mnx of Urethral Discharge & & & & \\
\hline b) & Drugs for Mnx of Genital ulcer disease (GUD) cases & & & & \\
\hline c) & Drugs for Mnx of Ophthalmia Neonatorum & & & & \\
\hline d) & Drugs for Mnx of cases of Vaginal Discharge or Pruritis & & & & \\
\hline e) & Drugs for Mnx of Lower abdominal pain in women & & & & \\
\hline f) & Determine & & & & \\
\hline g) & Bioline & & & & \\
\hline h) & Uni Gold & & & & \\
\hline
\end{tabular}




\begin{tabular}{|l|l|l|l|l|l|}
\hline i) & Laboratory reagents for(Urinalysis, & & & & \\
\hline j) & Full Haemogram reagents & & & & \\
\hline k) & IP Items & & & & \\
\hline I) & Acetic Acid & & & & \\
\hline m) & Loguls iodine & & & & \\
\hline n) & General supplies e.g gloves, Needle / Syringes,etc & & & & \\
\hline o) & Haematinics /suppliments & & & & \\
\hline p) & I.V FLUIDS & & & & \\
\hline q) & TRANSFUSION SERVICES & & & & \\
\hline r) & TB Drugs & & & & \\
\hline s) & Lignocaine & & & & \\
\hline t) & NVP Tabs & & & & \\
\hline u) & NVP Syrup & & & & \\
\hline v) & Cotrimoxazole Tabs /Syrup & & & & \\
\hline w) & AZT Tabs & & & & \\
\hline x) & AZT Syrup & & & \\
\hline y) & Others specify & & & & \\
\hline & Comments on RH/ HIV Commodity Procurements & & \\
\hline 1. & How do you ensure availability and adequacy of RH/HIV commodities and supplies & \\
\hline 2. & Is there a functional procurement committee/team? & & \\
\hline $3 . \quad$ What are the main challenges in the management of RH commodities? & & \\
\hline
\end{tabular}

\section{EQUIPMENT}

Observe and Indicate three priority RH/HIV related equipments that have been non functional for the last three months in the facility. Explore on the challenges and give suggestions on acquisition repair and maintenance as appropriate

\begin{tabular}{|l|l|l|l|}
\hline No. & Equipment & Point of use & Comment \\
\hline & & & \\
\hline & & & \\
\hline & & & \\
\hline
\end{tabular}

\section{SUPERVISION FOR QUALITY IMPROVEMENT}

1. Comment on how RH/HIV supportive supervision is conducted and whether feedback is given to the service provider

2. How often is RH/HIV supervision done? - Verify about availability of supervision schedule

3. Is there a functional quality improvement team for RH/HIV services?

4. What does the team do?

\section{MONITORING \& EVALUATION}

1. How do you ensure timely submission of your reports

2. Do you analyze the data collected?

3. How do you utilize the data?

4. What are the major challenges on data management? 


\section{LINKAGES/ REFERRAL AND COMMUNICATION SYSTEM}

1.Observe and comment on the client flow and linkages within/between service delivery points

2. Comment on Referral and tracking systems/tools

3. How do you get feedback about clients who are referred

4. What is the perception/attitude of the staff on their role in relation to referrals?

5. Comment on linkages with the community.

6. What are the challenges on referral and linkage of services?

\section{GENERAL ON OTHER RH/HIV PRIORITY AREAS}

Male involvement.

Comment on activities undertaken to increase awareness of RH/HIV services offered e.g Posters and Outreach services General facility infrastructure

Availability of other HIV/ RH services (Infertility services, youth friendly services, Home Based care services and Patient support centers)

RECOMMENDATIONS / SUGGESTIONS FOR IMPROVEMENT AND WAY FORWARD

\begin{tabular}{|l|l|l|}
\hline Action Points & Timeframe & Responsible person \\
\hline 1. & & \\
\hline 2. & & \\
\hline 3. & & \\
\hline 4. & & \\
\hline 5. & & \\
\hline
\end{tabular}

Date of the Subsequent Supervisory Visit

SUPERVISORY TEAM:

1.

2.

3.

4.

5.

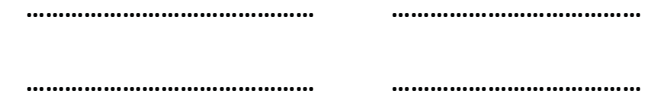


For more information, contact:

Project Director

APHIA II OR Project in Kenya

Population Council

General Accident Insurance House

Ralph Bunche Road

P.O. Box 1764300500

Nairobi, Kenya

Tel: 254202713480 - 3

Fax: 254202713479

www.popcouncil.org

\section{Population Council}

